\title{
Synthesis of an Atropisomeric HIV Integrase Inhibitor
}
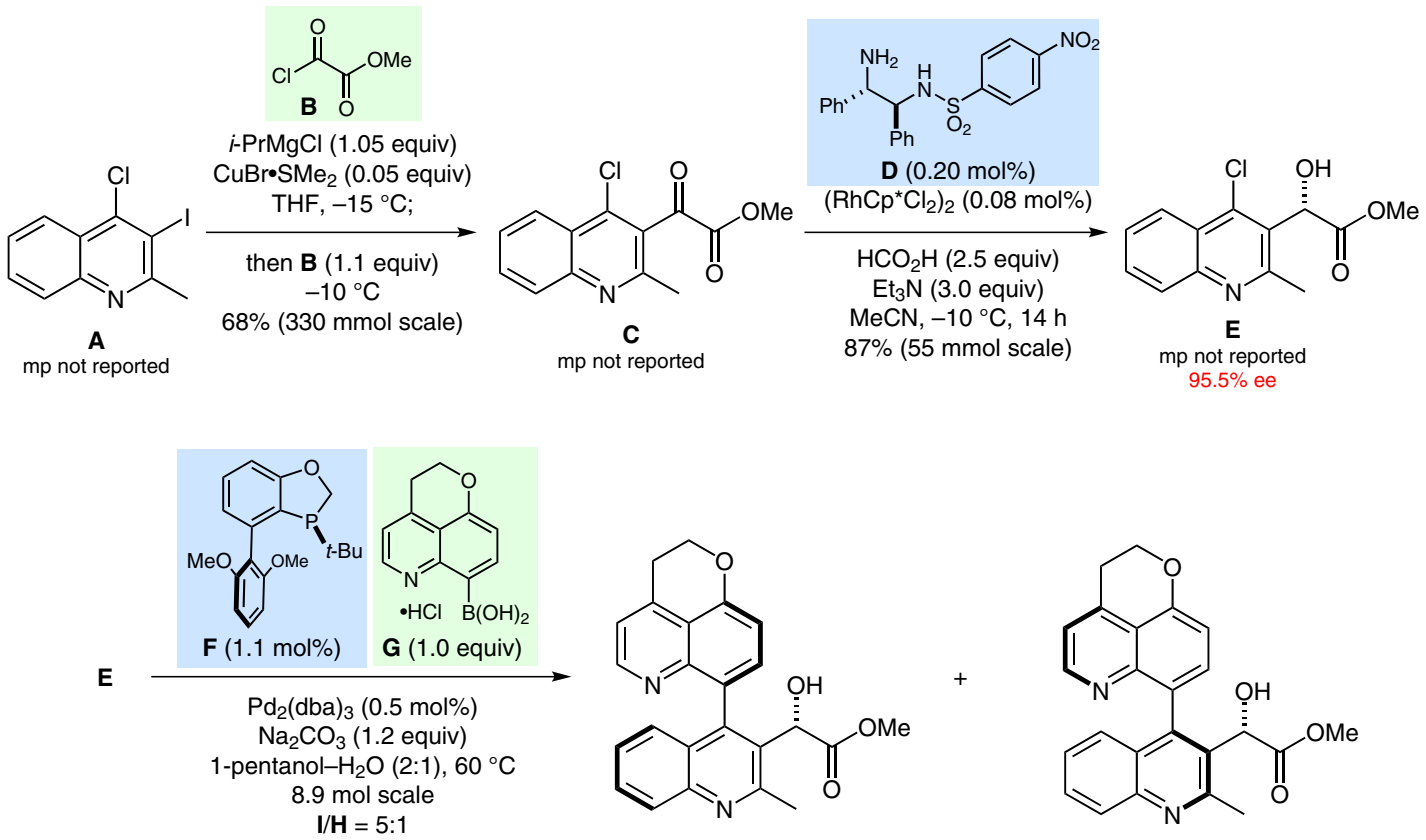

$73 \%$ isolated yield I $(\mathbf{I} / \mathbf{H}>95: 5)$ after crystallization<smiles>COC(=O)C(O)c1c(C)nc2ccccc2c1-c1ccc2c3c(ccnc13)CCO2</smiles>

H (minor) $\mathrm{mp}$ not reported<smiles>COC(=O)Cc1c(C)nc2ccccc2c1-c1ccc2c3c(ccnc13)CCO2</smiles><smiles>Cc1nc2ccccc2c(-c2ccc3c4c(ccnc24)CCO3)c1C(OC(C)(C)C)C(=O)O</smiles>

HIV Integrase Inhibitor mp not reported

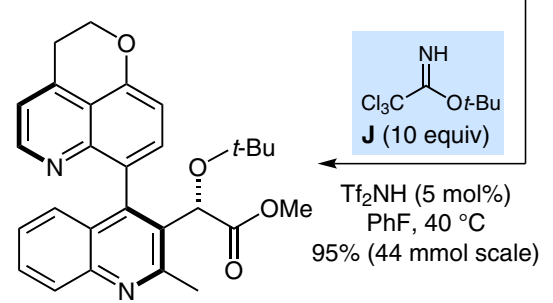

K

$\mathrm{mp}$ not reported
Significance: The target molecule is an atropisomeric integrase inhibitor that is of interest for the treatment of HIV. Noteworthy steps in the synthesis depicted include (1) a copper(I)-catalyzed acylation of quinoline A, (2) an asymmetric transfer hydrogenation of the $\alpha$-keto ester $\mathbf{C}$ mediated by the ligand $\mathbf{D}$, and (3) a ligand-controlled asymmetric Suzuki-Miyaura reaction mediated by the ligand $\mathbf{F}$.

\section{Category}

Synthesis of Natural

Products and

Potential Drugs

\section{Key words}

\section{HIV integrase}

inhibitor

transfer

hydrogenation

Suzuki-Miyaura

reaction

tert-butyl ethers

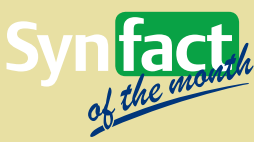

SYNFACTS Contributors: Philip Kocienski

Synfacts 2015, 11(8), 0789 Published online: 20.07.2015

Dol: 10.1055/s-0034-1381028; Reg-No.: K03615SF

Comment: The installation of the tert-butyl ether group on the bis(quinoline) scaffold of I was challenging, because intermediate I contains two basic nitrogen atoms and the tert-butyl ether is buried within a very sterically crowded environment. Best results were obtained using the trichloroacetimidate $\mathbf{J}$ together with bis(trifluoromethane)sulfonimide. 